\title{
$O$ direito à privacidade e os novos desafios da era da informação no século XXI
}

\author{
The right to privacy and the new challenges of the information age on \\ the $21^{\text {st }}$ century
}

\author{
ANDRei Fredes \\ Pontifícia Universidade Católica do Rio Grande do Sul - PUCRS
}

Mariana Borges

Centro Universitário Cenecista de Osório - UNICNEC

RESUMo A privacidade na era da informação é o tema central deste ensaio, especialmente a partir de sua vulnerabilidade percebida nos meios digitais, o que invoca a necessidade de um aprofundamento tendo em vista as transformações sociais que impactam a garantia de direitos e liberdades fundamentais. O artigo se divide em três momentos; o primeiro delimita a tradição na qual se constrói o direito à privacidade como garantia fundamental; o segundo momento apresenta a sociedade atual globalizada e difusa como antítese; finalmente, o terceiro momento busca a subsunção da tradição e da tecnologia em uma síntese capaz de responder os anseios sociais frente aos novos desafios propostos, especialmente o do perfilamento (profiling) massivo e de suas aplicações.

Palavras-chave: Privacidade; Informação; Direito Fundamental; Democracia.

\begin{abstract}
Privacy in the information age is the central theme of this essay, especially from its perceived vulnerability in digital media, which invokes the need for a deepening in view of the social transformations that impact the guarantee of fundamental rights and freedoms. The article is divided into three moments; the first delimits the tradition in which the right to privacy is constructed as a fundamental guarantee; the second moment presents the globalized and diffuse society as an antithesis; finally, the third moment seeks the subsumption of tradition and technology in a synthesis capable of responding to social longings in the face of new challenges proposed, especially massive profiling and its applications.
\end{abstract}

Keywords: Privacy; Information; Fundamental Rights; Democracy.

\section{INTRODUÇÃo}

Este ensaio possui como objetivo compreender o direito à privacidade a partir da ponte entre a tradição e o futuro na sociedade da informação. Dizendo de outra forma, o 
objetivo ao longo destas páginas é asseverar a importância cada vez maior de resguardar uma dimensão íntima ao ser humano, na qual ele possa escapar das tentativas cada vez mais inevitáveis de apropriação total do conjunto de dados pessoais, mas sem esquecer os fundamentos que construíram o direito à privacidade, especialmente nos séculos XIX e $\mathrm{XX}$, permitindo assim que se parta de uma tradição jurídica legítima para uma construção de um direito sólido.

O primeiro capítulo busca exatamente estabelecer esse conceito clássico de direito à privacidade, apresentando sua formação como parte de um ideal iluminista, ligado ao individualismo, bem como de um ideal social, fundado na ideia de estado democrático de direito. Percebe-se então as diversas dimensões aditivas que a privacidade foi adquirindo, desde o direito a ser deixado só, até a autodeterminação informativa.

A segunda parte pretende apresentar o novo momento no qual a privacidade passa a ser testada, sendo esse o momento da globalização e da sociedade da informação, na qual tudo passa a ser instantâneo e impossível de prever as consequências. A privacidade então precisa ser captada em seu horizonte de sentido e confrontada com essa nova realidade, para assim oferecer respostas capazes de atender aos anseios da sociedade atual.

A última parte dedica-se então a buscar aprofundar as questões com vistas ao futuro, especialmente a partir dos avanços da tecnologia que, por meio da captação de dados pessoais, desnudam a sociedade e parecem tornar a privacidade obsoleta, uma vez que corporações passam a saber mais sobre toda a população do que em qualquer momento da história. A partir daí se estabelecem perfis comportamentais - profiling - que passam a tratar os dados como produto e permitem compartimentar a sociedade em grupos, com objetivo de exercer as mais diversas influências sobre ela. Afetando desde a liberdade individual até, potencialmente, os rumos democráticos.

Em relação à metodologia, o presente artigo foi desenvolvido na forma de monografia, baseada em pesquisa bibliográfica documental, por meio de livros e artigos científicos acerca do assunto abordado.

\section{A CONFIGURAÇÃo das QUATRO DIMENSÕES do DIREITO À PRIVACIDADE}

A privacidade possui um lugar na sociedade há muito tempo, mas nem sempre teve o mesmo conceito, uma vez que, com o decorrer dos séculos e com a constante evolução social, novas vertentes foram moldadas conforme costumes e aspectos culturais (BOHRER, 2019, p. 17). Nesse sentido, como bem explica Doneda (2019, p, 29):

\footnotetext{
A noção de privacidade, em si, não é recente - com os diversos sentidos que apresenta, pode ser identificada nas mais variadas épocas e sociedades. Porém, a privacidade começou a ser concretamente abordada pelo ordenamento jurídico somente no final do século XIX para, enfim, assumir as suas feições atuais apenas muito recentemente. (DONEDA, 2019, p. 29).
}

Assim, pode-se perceber que ao longo dos anos o conceito de privacidade teve sentidos e abordagens diferentes, sendo tratado desde a perspectiva patrimonialista, muito relacionada com a posse de uma propriedade, até a de sua relação com o próprio indivíduo, seus direitos e liberdades. 
Conforme preceitua Doneda (2019, p. 113-114), durante a história da construção da privacidade, sua compreensão era feita a partir da separação do ambiente público e do privado. Insta ressaltar aqui que ainda não existia uma concepção de privacidade, mas, sim, de costumes que se apresentavam nos âmbitos da sociedade. Dessa forma, na Antiguidade Clássica Grega, já podíamos visualizar a dicotomia público-privado, porém, de uma forma diversa.

$\mathrm{Na}$ Grécia, esses dois setores da sociedade eram autônomos e separados, sendo que o público era destinado para atuações na pólis e, por sua vez, o âmbito privado era ligado à vontade humana em sua natureza, bem como a relação material de possuir um lugar seu. Portanto, era na vida pública da pólis que o indivíduo podia expressar seus pensamentos, sendo considerado um lugar de iguais - homens livres, os quais eram minoria na sociedade -, enquanto a esfera privada, não tão valorizada, era reservada para atividades do lar, na qual a desigualdade imperava (BOHRER, 2019, p. 19).

Observando os ensinamentos de Benjamin Constant (1819), na Roma antiga a população deliberava sobre os assuntos afetos à organização social em praça pública, onde detinham o poder principal daquela sociedade, todavia, em contraponto com essa liberdade na esfera pública, a vida privada era submetida aos olhos de todos, e a liberdade estava à sorte dos julgamentos da sociedade. Aqui, podemos notar que os antigos percebiam a liberdade de uma forma diferente, colocando em primeiro lugar seus direitos políticos e abdicando, assim, de sua independência individual.

Já na Idade Média, durante a ascensão da Igreja Católica e a fortificação dos senhores feudais, uma noção de privacidade começa a se formar, ainda que não evidentemente reconhecida, é possível perceber alguns traços que demonstravam o anseio pela intimidade. Para Danilo Doneda (2019, 115-116), no decorrer da Idade Média não havia uma aspiração pré-ordenada pela privacidade, podia-se vislumbrar somente que poucos indivíduos tinham a prerrogativa do isolamento como, por exemplo, alguns senhores feudais que, exemplificando tal manifestação, tinham o costume de retirarem-se da sala de jantar comum para fazerem as refeições em um local privado.

Será no final da Idade Média que poderemos observar, de forma mais clara, manifestações que indicam o surgimento de uma esfera privada, a qual começa a delinear-se como raiz dos moldes atuais. Nesse sentido, Rodotà (2008, p. 26) destaca que:

[...] o nascimento da privacidade pode ser historicamente associado à degradação da sociedade feudal, na qual os indivíduos eram todos ligados por uma complexa série de relações que se refletiam na própria organização de sua vida cotidiana: o isolamento era privilégio de pouquíssimos eleitos ou daquele que, por necessidade ou opção, viviam distantes da comunidade - místicos ou monges, pastores ou bandidos. (RODOTÀ, 2008, p. 26).

Assim, no século XVI pode-se observar o nascer de uma mudança de costumes. Uma das linhas de tal modificação relaciona-se com as novas disposições arquitetônicas das casas e cidades, as quais permitiam uma separação por classes e categorias (DONEDA, 2019, p. 117). Logo, consoante aduz Rodotà (2008, p. 27), a possibilidade de isolamento agora alcança aqueles que possuem meios materiais para dispor de um local que satisfaça o desejo de isolamento. A privacidade, assim, dá à classe burguesa a possibilidade de usufruir da 
própria intimidade, de modo que fortalecendo o individualismo, fazia com que a burguesia se diferenciasse das demais classes.

A propriedade então passa a ser o cerne do conceito de privacidade, tendo em vista que esta lograva ser obtida com o resguardo proporcionado pelo isolamento de um local somente seu (DONEDA, 2019, p. 122). Importante se faz ressaltar o fato de que classes mais pobres não tinham essa prerrogativa de privacidade, já que, por muitas vezes, não possuíam um local com estrutura para lhes proporcionar a famosa vida privada.

Nos caminhos trilhados pela privacidade, deve-se ressaltar o clássico artigo "The right to privacy", dos juristas Warren e Brandeis (1890), os quais se encontrando no meio de mudanças ao final do século XIX, com a vinda das fotografias, jornais e mudanças na comunicação, defendiam a proteção do indivíduo contra as interferências externas, cada vez mais presentes na sociedade. O ponto central da discussão do artigo é a proteção da privacidade sob a curiosidade de terceiros, vez que a família de Warren estava constantemente em noticiários da época (PUPO, 2017, p. 13).

Quanto ao artigo de Warren e Brandeis, é importante dizer que os autores, àquela época, ainda não lograram anunciar uma prerrogativa do direito à privacidade como regra de fato, ou seja, não restou fundada uma base jurídica de regulamentação que contivesse a previsão de um direito à privacidade ou que conceituasse tal direito. Warren, vendo-se vítima dos holofotes da mídia, vez que o seu nome e de sua família estavam constantemente nos jornais impressos, juntamente com seu sócio Brandeis (1890) e, contando com a influência de outros escritos como, por exemplo, a obra de um magistrado norte-americano, Thomas Cooley, marcaram a história da privacidade, estabelecendo uma ligação entre o direito à privacidade e à personalidade do indivíduo, o que apontou um início do afastamento da relação privacidade x propriedade, abordando, em sua construção teórica, um lado não muito explorado ainda à época, no sentido de que o direito à privacidade estava conectado com a personalidade de um indivíduo, bem como, consequentemente, poderia ser afetada quando certos fatos da vida privada chegassem ao conhecimento de terceiros (PEIXOTO, 2020, p. 395).

Martins e Hosni destacam que a questão da ligação da privacidade e propriedade por muito tempo ficou intrinsecamente posta na sociedade (MARTINS; HOSNI, 2019). As decisões acerca da proteção da intimidade eram restritas e estavam muito vinculadas com o caráter patrimonial e com o resquício de sua identidade burguesa, sendo assim pelo menos até a década de 1960.

Foi somente com o surgimento do bem-estar social, durante o século XX, que a privacidade começou a se relacionar efetivamente com a pessoa em si e sua personalidade, a partir daí, qualquer cidadão poderia ser afetado pela violação da privacidade, vez que o Estado e as entidades privadas não visavam mais a informação alheia somente como fonte de fofoca, mas sim como meio de obter vantagens no mundo econômico ou político. Logo, ao passo que a tecnologia ia se desenvolvendo e aumentando seu poder de processamento de informações, estas aumentavam constantemente o seu valor (DONEDA, 2019, p. 33).

Destarte, a defesa da privacidade, a partir desse momento, passa a ganhar um novo significado, dependendo de qual seja o objetivo pretendido por meio da coleta de informações, Rodotà (2008, p. 29) explica bem essa situação: 
A mudança das motivações altera o significado da invocação: no primeiro caso, recusando as informações necessárias aos programas de intervenção social, a privacidade apresenta-se como um instrumento para a consolidação dos privilégios de um grupo; no segundo caso, serve para reagir contra o autoritarismo e contra uma política de discriminações baseada nas opiniões políticas. (RODOTÀ, 2008, p. 29).

Assim, podemos dizer que temos o rompimento das raízes burguesas do conceito de privacidade, vez que essa passa a ser uma forma de promoção da igualdade, na qual o isolamento dentro de uma propriedade não é mais suficiente frente às mudanças sociais, como bem expõe Laura S. Mendes (2014, Edição Kindle), "De um direito com uma dimensão estritamente negativa e com uma conotação quase egoísta, passou a ser considerado uma garantia de controle do indivíduo sobre as próprias informações e um pressuposto para qualquer regime democrático".

Percorrendo brevemente esse caminho trilhado pela privacidade, importante notabilizar o momento identificado como pós-guerra, no século XX, no qual as tecnologias começaram a ser utilizadas para dar origem ao início da internet. Conforme colaciona Castells, a rede de computadores que contribuiu com o nascimento da internet foi implementada pela ARPA, Agência formada pelo Departamento de Defesa dos Estados Unidos, a qual visava a realização de pesquisas voltadas para o desenvolvimento da tecnologia militar (CASTELS, 2003). Dessa maneira, marco da criação computacional e o desenvolvimento da tecnologia aborda uma nova mutação na forma de ver a privacidade, vez que em pouco tempo a forma de processamento das informações foi amplamente aumentada.

Para finalizar, necessário faz nos atentarmos à uma última consideração. Inicialmente, deve-se restar cristalino que o modo como a privacidade é conceituada está estreitamente ligado às possibilidades de interferência na liberdade de um indivíduo (PUPO, 2017 , p. 09). Como exposto acima, a privacidade percorreu um longo caminho até chegar em sua forma atual, assim, enfatizando o caráter fenomenológico do Direito, no qual o verdadeiro conteúdo se forma a partir da fusão de horizontes (GADAMER, 2015) entre norma e prática social.

As correntes de conceituação da privacidade ao longo do tempo formaram a base desse direito. É possível definir o conteúdo do Direito à privacidade em quatro dimensões. A primeira, o direito de ser deixado só, marcado pelas novas formas de comunicação como os jornais, bem como pela possibilidade das fotografias, datada do século XIX, aspecto defendido por Warren e Brandeis, já citados acima. A segunda, a privacidade a respeito do aspecto do controle sobre as informações, visível a partir do século XX, em que o Estado passa a ter novas atribuições perante a sociedade, onde somente o isolamento não se faz mais suficiente como forma da proteção da privacidade. A terceira corrente, o direito de manter o segredo da informação, tem o conceito da privacidade voltado para o direito do cidadão em deliberar sobre quais fatos pessoais o público poderá ter acesso. Por fim, a quarta corrente apresenta a noção de autodeterminação informativa, na qual o indivíduo passa a ter o direito de controle sobre suas informações (PUPO, 2017, p 12-19).

A partir do aspecto da última vertente, Maria Celina Bodin de Moraes (RODOTÀ, 2008, p. 7) ilustra que o referido direito de controle sobre suas informações determina a 
construção da própria esfera privada, sendo uma ferramenta essencial para o estabelecimento da igualdade, liberdade e não discriminação.

Percebe-se que todas essas correntes foram sendo sucessivamente construídas e se apoiando umas nas outras conforme as mudanças sociais requeriam, seguindo o movimento pendular da dialética sempre presente entre a norma e a sociedade, possibilitando a adequação do conceito em face ao que cada época demandava. Dessa forma, considerar somente uma delas não é suficiente, do mesmo modo que deve-se sobrepesar os aspectos de cada uma, a fim encontrar um conceito que abranja o direito à privacidade de forma a equilibrar os interesses da era digital e concretizar o direito à vida privada como inerente ao desenvolvimento da personalidade e pessoalmente ligado ao exercício do direito da dignidade de pessoa humana.

\section{A PRIVACIDAde E A SOCIEDAdE DA INFORMAÇÃo}

O avanço da tecnologia nos trouxe até o momento atual. Denominada por autores como sociedade da informação (LYON, 1998, p. 384-402) ou sociedade de vigilância (FOUCAULT, 1987, p. 240), o certo é que hoje estamos cotidianamente compartilhando e recebendo muitas informações.

Para chegarmos à privacidade que temos hoje, grandes marcos internacionais abordaram-na como um verdadeiro direito humano. A Declaração Universal de Direitos Humanos (DUDH, Online), em 1948, já previa em seu texto que:

Art. 12: Ninguém será sujeito a interferências em sua vida privada, em sua família, em seu lar ou em sua correspondência, nem a ataques à sua honra e reputação. Todo ser humano tem direito à proteção da lei contra tais interferências ou ataques. (DUDH, Online)

Assim como a Declaração Universal de Direitos Humanos, o julgamento feito pelo Tribunal Constitucional Alemão, em 1983, referente à Lei do Censo ${ }^{1}$ foi de grande valia para o cenário atual, uma vez que restou aqui implementada a noção de autodeterminação sobre a informação, a qual foi posta como condição mínima para o livre desenvolvimento da personalidade.

Atualmente, em âmbito nacional, o direito à privacidade encontra-se positivado no artigo 5 , inciso X, da Constituição da República Federativa do Brasil (1988), que preceitua "são invioláveis a intimidade, a vida privada, a honra e a imagem das pessoas, assegurado o direito a indenização pelo dano material ou moral decorrente de sua violação."

\footnotetext{
A sentença da corte alemã sobre a Lei do Censo é até hoje uma grande referência no campo da proteção de dados. A decisão declarou inconstitucional a então lei que previa o recenseamento da população, na qual cada cidadão teria que responder 160 perguntas relacionadas à profissão, moradia e trabalho, a serem posteriormente submetidas a tratamento. Pode-se destacar que alguns argumentos utilizados na sentença foram em relação à proteção da autodeterminação informativa, bem como quanto à falta de uma finalidade para o tratamento de dados que a lei previa. Decisões do Tribunal Constitucional Federal. v. 1, p. 56 ss. (BVerfGE $65,1)$. In: Martins, Leonardo. Tribunal Constitucional Federal alemão: decisões anotadas sobre direitos fundamentais. v. 1: Dignidade humana, livre desenvolvimento da personalidade, direito fundamental à vida e à integridade física, igualdade. São Paulo: Fundação Konrad Adenauer, 2016.
} 
A expansão da internet veio para mudar a visão de privacidade, dados contendo diversificadas informações sobre os indivíduos podem ser armazenados em grandes quantidades nos bancos de dados, seja de entidades públicas ou privadas. Portanto, considerando que os meios de atingir a vida privada são aprimorados a cada ano, novas respostas para os problemas que podem surgir devem ser formuladas e, nesse caso, não só respostas posteriores aos problemas, mas respostas preparadas como forma de prevenção a possível lesão ao direito de privacidade do indivíduo (DONEDA, 2019, p. 39-44).

Assim, seguindo o contexto de privacidade que foi estabelecido ao longo dos anos, conforme demonstrado no tópico anterior, partindo do momento em que sua concepção foi ligada à pessoa detentora de direitos, primeiramente como um direito de ser deixado só (WARREN; BRANDEIS, 1890), representado por um aspecto negativo, ou seja, a partir de uma não interferência externa na privacidade do indivíduo, e, posteriormente, no âmbito atual, pela Constituição Federal que trouxe a proteção da intimidade, privacidade, honra e imagem, em seu artigo $5^{\circ}$, inciso $\mathrm{X}$, podemos perceber que somente tal concepção não encontra mais sustentação quando aplicada às relações da sociedade atual, devendo ser respaldada por novos direitos.

Essa, então, deve passar a ser vista como um direito baseado em uma ação do cidadão, o qual passa a ter controle sobre suas informações (COSTA; OLIVEIRA, 2019, p. 38). No mesmo sentido, Rodotà (2008, p. 92) ressalta que "a privacidade pode ser definida mais precisamente, em uma primeira aproximação, como o direito de manter o controle sobre as próprias informações."

Em contrapartida ao encontro dos posicionamentos retro mencionados, a sentença sobre o censo alemão relata que a autodeterminação informativa vai além da proteção da privacidade, dando ao indivíduo o poder sobre a entrega e utilização de seus dados pessoais (MARTINS, 2016).

Apesar de ser difícil manter um conceito de privacidade, tendo em vista sua variabilidade em razão do avanço tecnológico e consequentes mudanças na estrutura da sociedade e como ela se comunica, realizando constantemente a atualização dialética já mencionada, deve-se observar o que salienta Baião e Gonçalves (2014, p. 15):

\footnotetext{
A tecnologia, todavia, não deve ser um problema, mas sua presença deve ser construída a partir do diálogo, da intersubjetividade, a fim de que a técnica não venha representar uma perda de identidade pessoal. De igual forma, a privacidade não é um obstáculo, antes se apresenta como a via pela qual as inovações científicas e tecnológicas podem legitimamente entrar em nossa sociedade e em nossas vidas. (BAIÃO; GONÇALVES, 2014, p. 15).
}

De toda sorte, é necessário se ter em mente acerca do direito à privacidade, assim como qualquer outro direito subjetivo, que ele se insere em uma tradição jurídica, definida pela norma que se pretende realizar. Não é possível operar uma cisão entre texto e norma, mas sim desvelar a forma como a norma vem a se subsumir em cada novo movimento dado, seja pela alteração legislativa de um lado, ou pela alteração da realidade na qual essa norma é aplicada. De qualquer forma, a síntese inevitavelmente reconstrói a jurisprudência constantemente, mas sempre a partir daquela tradição já posta (STRECK, 2014). 
Compreende-se, portanto, que o direito à privacidade foi se expandindo, englobando a proteção dos dados pessoais, dialogando com as novas modalidades do mundo da informação. Não obstante, imprescindível mencionar que o direito à privacidade, por sua condição pioneira e status de direito fundamental, veio ao longo dos anos se estendendo para dar base à proteção de dados pessoais, todavia, na atualidade, devemos ter em mente que a proteção dos dados não se dá de maneira simples e muito menos deve ser deixada de lado, sendo caracterizada como um subtipo do direito à privacidade, mas sim sendo pensada como um direito autônomo, uma vez que, conforme Costa e Oliveira (2019, p. 29):

\section{[...] a proteção de dados pessoais ergue-se como a tutela da "própria dimensão relacional da pessoa humana", pois existe um leque vasto de liberdades indivi- duais relacionadas com a proteção de dados pessoais, que extrapolam os limites de tutela do direito à privacidade [...]. (COSTA; OLIVEIRA, 2019, p. 29).}

Sabe-se que o direito pátrio tem como seu princípio basilar a proteção da dignidade da pessoa humana, bem como que o artigo $5^{\circ}$, inciso X, da Constituição Federal, apresenta a prerrogativa da inviolabilidade da intimidade, vida privada, honra e a imagem das pessoas (DONEDA, 2019, p.44).

Nessa perspectiva, o crescimento da utilização dos dados pessoais, contendo informações inerentes aos indivíduos, demonstra a grande importância da regulação da proteção das informações pessoais da pessoa no ciberespaço, uma vez que com o corrente avanço tecnológico, o direito à privacidade emerge como alicerce essencial para uma sociedade democrática, tendo em vista que é por meio do livre exercício da personalidade e expressão que ela se baseia (SANTIN; MAGRO; FORTES, 2017, Online).

Nas últimas décadas foi possível notar que passamos de um cenário no qual a preocupação com a privacidade advinha de um temor de que as informações pessoais saíssem do âmbito privado e chegassem a terceiros, para um mundo no qual a privacidade é vista como meio de preservar direitos, interesses e valores. Nessa seara, Danilo Doneda (2019, p. 42) explica que:

[...] a proteção da privacidade na sociedade da informação, a partir da proteção de dados pessoais, avança sobre terrenos outrora improponíveis e nos induz a pensa-la como um elemento que, mais do que garantir isolamento ou a tranquilidade, serve a proporcionar ao indivíduo os meios necessários à construção e consolidação de uma esfera privada própria [...]. (DONEDA, 2019, p. 42).

A era digital, portanto, ressalta uma nova vertente para o direito da privacidade, outrossim, observa-se que as tecnologias da informação foram evoluindo de forma tão rápida que não foi possível que os estudos e pesquisas fossem atualizados e utilizados para formar uma ferramenta totalmente segura, dessa forma, ao mesmo tempo que a sociedade em rede trouxe maior liberdade e expandiu o acesso à informação, trouxe, também, problemas técnicos, econômicos, políticos, sociais e jurídicos a serem enfrentados (MENDONÇA, 2014, p. 07).

Partindo da noção mais atualizada de entender a privacidade, qual seja, sob o aspecto da autodeterminação informativa, na qual o indivíduo exerce controle sobre suas informações pessoais, tem-se que o direito à privacidade engloba uma nova exigência da sociedade 
informacional em que seu exercício implica na efetivação da liberdade individual e construção da própria identidade. $\mathrm{O}$ aumento no fluxo das informações foi o que ocasionou essa nova forma de ver a privacidade que, portanto, deve ser somada ao direito à proteção de dados pessoais, para que se possa ter um panorama da proteção informacional do cidadão.

Ademais, é importante destacar que um perigo advindo dessa nova demanda da sociedade tecnológica é a banalização da privacidade, na qual é posta de lado, em detrimento do acesso à tecnologia, nesse sentido, Danilo Doneda $(2019$, p.39) salienta que:

Esse processo, ao mesmo tempo, pode ser entendido como uma tentativa de neutralização do impacto tecnológico, cujo objetivo seria a lenta absorção pela sociedade de uma perspectiva na qual a privacidade é menos relevante, fazendo com que a sua erosão fosse ao cabo admitida como uma "consequência natural" - um fato da vida, naturalizado pela valorização de determinados valores da sociedade de consumo. (DONEDA, 2019, p. 39).

Em uma era de tantas inovações, os pensamentos sobre a privacidade e proteção de dados devem, igualmente, impor novidades e possibilidades diversas. Assim, as discussões sobre como a privacidade se amolda à sociedade digital não devem se dar por acabadas, vez que estarão sempre em reconstrução, a fim de alcançar uma compreensão cada vez maior dos efeitos que as tecnologias da informação e comunicação podem causar na sociedade. Nessa perspectiva, Marcel Leonardi argumenta que "A internet e outras tecnologias de informação podem não ter, ainda, acabado com a privacidade; no entanto, elas redefiniram o que o termo significa" (LEONARDI, 2011, p. 42).

A constante utilização de novas tecnologias permite que a violação da privacidade fique cada vez mais fácil, tornando possível que formas tradicionais de controle político e organizacional sejam lançadas sobre o usuário (CASTELLS, 2003, p. 175).

Partindo dessa premissa, a privacidade, então, altera sua função sociopolítica e impõe-se não somente como um direito concernente à esfera privada, mas como um componente que constrói a cidadania e a identidade pessoal. Ademais, o modo como ela é protegida é o caminho para a formação da sociedade atualmente, podendo, inclusive, influenciar na participação política (RODOTÀ, 2008, p. 129).

Apesar de todas as tentativas de pensar em uma forma de resguardar o cidadão de interferências na privacidade, devemos ter em mente que, mesmo com as inovações legislativas e doutrinárias, o cidadão continua em certa desvantagem perante as grandes organizações e setores políticos, demonstrando uma relação assimétrica, alertando que o controle total do indivíduo sobre as suas próprias informações pessoais coletadas é, de certa forma, ilusório (MACHADO, 2014, p. 349). O que, de qualquer forma, não deve impedir ou desestimular a procura por uma proteção da privacidade, liberdade e personalidade do cidadão.

Por fim, finaliza-se esse capítulo com os ensinamentos de Rodotà (2008, p. 129), o qual mostra como a privacidade deve ser vista hoje:

- Impõe-se como direito fundamental;

- Especifica-se como direito à autodeterminação informativa e, mais precisamente, como direito a determinar as modalidades de construção da esfera privada na sua totalidade; 
- Apresenta-se, por fim, como precondição da cidadania na era eletrônica e, como tal, não pode ser confiada unicamente à lógica da auto-regulamentação ou das relações contratuais. (RODOTÀ, 2008, p. 129).

Identifica-se então que a privacidade foi vista de diversos modos ao longo do tempo e que cada alteração da sociedade muda o aspecto da sua tutela. Ainda, entende-se que se deve compreender que todas as conceituações da privacidade elaboradas ao longo dos anos são válidas para formar um pensamento que gere uma proteção mais abrangente possível na era atual.

$\mathrm{O}$ direito à privacidade, deve ser cumulado com a noção de autodeterminação informativa e precisa ser percebido em conjunto com suas demais facetas, como a proteção de dados pessoais, vez que suas funções atingem direitos como o da personalidade, o qual, por sua vez, recai sobre uma teia de outros direitos fundamentais dos indivíduos, como o direito à dignidade da pessoa humana.

\section{O PROFILING E O FIM DA PRIVACIDADE?}

O crescimento exponencial do fluxo de dados pessoais, advento da evolução da tecnologia, traz consigo novas consequências, uma vez que o aumento do número de dados armazenados faz surgir inovações para seu processamento, cada vez mais eficiente e direcionado (BOHRER, 2019, p. 75).

O modelo de negócios das redes sociais transformou os dados e as informações pessoais dos indivíduos em um produto de alto valor. O implemento da tecnologia e a possibilidade da compilação e análise de grandes números de dados pessoais, origina um - novo - modelo de economia, no qual os cidadãos são meros espectadores perante a coleta de seus próprios dados (BIONI, 2019, p. 39).

Sabe-se que a maioria das plataformas digitais são acessadas, em tese, de forma gratuita, todavia, a situação não é tão simples assim. Para que uma plataforma seja economicamente viável e rentável os clientes de um dos lados precisam representar algum valor para os clientes do outro lado como, por exemplo, uma plataforma que administra a relação entre o usuário e o anunciante. Dessa forma, após a experiência da sociedade nas plataformas digitais, pode-se advertir que, em um primeiro momento, uma plataforma não tem um custo aparente, no entanto, analisando melhor, é possível visualizar que, na maioria das vezes, existem custos obscuros para a utilização dos serviços, quais sejam, os dados pessoais dos usuários (KREIN, 2018, p. 202).

Os dados estão disponíveis em vários lugares hoje em dia, Britany Kayser, ex-integrante da empresa Cambridge Analytica, relata em seu livro uma frase dita pelo ex-gerente da empresa, a qual demonstra como as empresas especialistas em marketing comportamental estão visualizando os dados pessoais: "Bater de porta em porta não é a única maneira de obter dados agora. Os dados estão por toda a parte. E agora todas as decisões são baseadas neles." (KAISER, 2020, p. 73).

Para ilustrar ainda melhor essa nova realidade, no qual a cada movimento que é realizado deixa-se uma espécie de rastro digital, uma informação sobre si mesmo, o autor Jaron Lanier (2018, p. 13) expõe: 
Os algoritmos se empanturram de dados sobre você a cada segundo. Em que tipos de links você clica? Quais são os vídeos que vê até o fim? Com que rapidez pula de uma coisa a outra? Onde você está quando faz essas coisas? Com quem está se conectando pessoalmente e on-line? Quais são as suas expressões faciais? Como o tom da sua pele muda em diferentes situações? O que você estava fazendo pouco antes de decidir comprar ou não alguma coisa? Você vota ou se abstém? Todas essas informações e muitas outras têm sido comparadas a leituras semelhantes sobre a vida de milhões por meio de uma espionagem maciça. Os algoritmos correlacionam o que você faz com o que quase todas as outras pessoas têm feito. (LANIER, 2018, p. 13)

Assim, a maciça coleta de dados e os desenvolvimentos tecnológicos cada vez mais constantes para seu armazenamento e tratamento, abrem novas possibilidades para a utilização de técnicas computacionais que gerem a melhor utilização possível das informações obtidas.

As técnicas de data mining e de profiling, respectivamente traduzidas como mineração de dados e perfilamento on-line, são ferramentas que, dentre tantas outras, permitem a utilização da captação de dados pessoais para diversas abordagens como, por exemplo, o microtargeting.

O data mining é a técnica que, com base em dados brutos, realiza correlações, estabelece padrões e pressupõe tendências, tudo isso é possível por meio de mecanismos estatísticos e matemáticos (BOHRER, 2019, p. 76). Dessa forma, a partir de uma grande demanda de dados que antes não tinham um significado, o data mining promove uma classificação e gera uma informação útil. Nesse sentido, como bem exemplificam Castro e Ferrari (2017, p. 45):

O termo mineração de dados (MD) foi cunhado como alusão ao processo de mineração descrito anteriormente, uma vez que se explora uma base de dados (mina) usando algoritmos (ferramentas) adequados para obter conhecimento (minerais preciosos). (Castro e Ferrari, 2017, p. 45)

Por sua vez, a técnica do profiling é baseada na mineração de dados, sendo resultado do avanço tecnológico. Conforme preceitua Doneda (2019, p. 151), tal método consiste na construção de perfis de comportamento de um indivíduo, o qual é elaborado a partir dos dados pessoais disponibilizados ou captados, como bem sintetiza o autor:

Com ela, os dados pessoais são tratados com o auxílio de métodos estatísticos e de técnicas de inteligência artificial, com o fim de se obter uma "metainformação", que consistiria numa síntese dos hábitos, preferências pessoais e outros registros da vida desta pessoa. O resultado pode ser utilizado para traçar um quadro das tendências de futuras decisões, comportamento e destino de uma pessoa ou grupo.(DONEDA, 2019, p. 151)

A partir desse aspecto, variadas são as utilizações da elaboração de um perfil online, podendo ser aplicados desde o âmbito mercadológico, no direcionamento de marketing comercial, ou até influenciar na operação da política e das eleições, direcionando um grupo de pessoas a um comportamento esperado (HOSTERT, 2018, p. 31). 
Como podemos perceber, esse ciclo informacional proporcionado pelos avanços tecnológicos possui um ativo de extrema importância: os dados pessoais. Há um ciclo, porque podemos observar a seguinte linha de acontecimentos: acesso à plataforma $\rightarrow$ fornecimento direto ou indireto dos dados $\rightarrow$ captação e tratamento dos dados $\rightarrow$ informação compilada e analisada do próprio usuário pode ser convertida em forma de publicidade ou pode auxiliar na classificação dos conteúdos que aparecem com maior frequência para ele. Visualizando assim, o dado pessoal é o ator de maior importância nessa cadeia e, por isso, a grande importância de sua proteção.

Conforme abordado acima, o profiling é a técnica que logrará elaborar um perfil do indivíduo. Tal método fará isso com base no cruzamento dos dados coletados com outros dados já existentes e com base em estatísticas, sendo que os algoritmos são considerados uma peça chave para esse caminho. Assim, no final do processo há a compilação de muitos dados, resultando em uma informação sobre preferências do usuário, o que, por sua vez, possibilitará uma previsão comportamental do indivíduo (MACHADO, 2018, p. 129). Nessa perspectiva, Laura Schertel (2014, Edição Kindle) aborda:

[...] a construção de perfis compreende a reunião de inúmeros dados sobre uma pessoa, com a finalidade de se obter uma imagem detalhada e confiável, visando, geralmente, à previsibilidade de padrões de comportamento, de gostos, hábitos de consumo e preferências do consumidor.(MENDES, 2014, Edição Kindle)

Com a elaboração do perfil pronta, é possível, então, a organização de um padrão comportamental, bem como a previsão de uma tendência de comportamento de um usuário ou de um grupo de usuários com atitudes similares (MACHADO, 2018, p. 130).

Por meio da técnica do perfilamento as empresas de marketing podem produzir um conteúdo personalizado, com base no perfil que foi montado do indivíduo ou de um grupo e veiculá-la, customizando e direcionando, assim, conteúdos preestabelecidos que induzam o usuário a clicar, tal estratégia é conhecida como microtargeting ou publicidade direcionada.

Ao longo dos anos a ciência por trás das publicidades mercadológicas foi percebendo que a comunicação em massa não era mais tão eficiente, gastava-se recursos que não traziam tanto retorno, vez que se desperdiçava esforços com alguém que não estaria tão inclinado a compra de determinado produto. Nessa linha de pensamento foi que surgiu a ideia da publicidade direcionada, na qual seria possível a identificação prévia dos consumidores que efetivamente poderiam ter interesse em comprar o serviço oferecido, para que assim pudessem canalizar os esforços em um público específico (BIONI, 2019, p. 41).

Assim, observando as considerações do autor Bruno Bioni $(2019$, p. 42) "[ [... a publicidade direcionada é uma prática que procura personalizar, ainda que parcialmente, tal comunicação social, correlacionando-a a um determinado fator que incrementa a possibilidade de êxito da indução ao consumo.”.

Com a viabilidade da coleta massiva de dados pessoais na sociedade da informação, a construção de um perfil por meio dos métodos elencados acima pode representar uma pessoa de forma virtual. Tal reprodução pode ser seu único aspecto palpável perante terceiros, podendo, inclusive, confundir-se com o próprio indivíduo (DONEDA, 2019, p. 152).

Logo, a elaboração do perfil de uma pessoa a partir da captação de suas informa- 
ções constitui-se, atualmente, como uma representação da personalidade do indivíduo no mundo digital (COSTA; OLIVEIRA, 2019, p. 32), os ímpetos mais íntimos e privados estão esboçados nas redes que são usadas diariamente, sendo um elo entre a pessoa e o ambiente digital externo.

Portanto, partindo da premissa na qual o usuário é monitorado e fornece dados das mais variadas formas todos os dias, os quais são analisados e utilizados para personificação do conteúdo, pode-se considerar que tais fatores podem causar uma diminuição na esfera da liberdade do indivíduo, vez que suas possibilidades de escolha estão cerceadas pela visão que é formada a partir do profiling, bem como, pode-se notar que há uma barreira na chegada de informações até o usuário. Assim, quando tais técnicas ultrapassam a esfera do marketing de vendas e começam a ser utilizadas no âmbito político, coloca-se em risco outros importantíssimos direitos atinentes ao ser humano.

São direitos previstos constitucionalmente a liberdade de expressão, a privacidade e os atinentes à personalidade, todos inerentes ao ser humano e vinculados com o princípio basilar da dignidade da pessoa humana. Esses três direitos estão intrinsecamente ligados ao cerne dessa questão, a partir do fato de que todos possuem o direito de se expressar livremente, inclusive no meio digital, seguindo a análise, igualmente, todos possuem a prerrogativa do resguardo de sua intimidade e, por fim, cada ser humano possui direitos atinentes a sua personalidade (a honra, a imagem, o nome e a integridade física e psíquica) (COSTA; OLIVEIRA, 2019, p. 29-30).

Feita essa ligação fundamental, observa-se que a captação de dados pessoais e a utilização de técnicas para elaboração de um perfil dão margem para o direcionamento manipulado de informações externas que chegam até o indivíduo, tendo em vista que, a partir de programas que preveem o comportamento do usuário, os administradores dessas tecnologias podem veicular notícias ou informações preestabelecidas, criando uma espécie de bolha digital, ferindo a liberdade e livre construção da identidade da pessoa (DONEDA, 2019, p. 152).

O fenômeno da chamada bolha digital pode ser exemplificado pelo modo como a rede social Facebook disponibiliza os conteúdos no feed de notícias ou linha do tempo. As plataformas passaram a utilizar os algoritmos para classificar conteúdos que poderão ser de maior interesse do usuário, os quais aparecerão com maior prevalência quando o usuário acessar a rede (NETO, 2016, p. 208). Dessa forma, os usuários acabam presos em espaços digitais em que são mostrados conteúdos que se adequem com suas preferências e opiniões, ademais, tais conteúdos podem ser utilizados também para induzir a determinados pensamentos.

Nesse sentido, conforme Rodotà (2008, p. 15-17) explica, a autonomia do indivíduo na sociedade da informação deve ser reivindicada, colocando em foco a "autodeterminação informativa" do cidadão, devendo este ter o direito de controle sob suas informações e como elas são captadas e controladas.

O Tribunal Constitucional Alemão, no ano de 1983, ao decidir sobre a constitucionalidade da Lei de Recenseamento de População, Moradia e Trabalho, reconheceu o direito à autodeterminação informativa, colocando o cidadão como peça principal no processamento de seus dados pessoais (OLIVEIRA, 2020, p. 166).Laura Schertel Mendes traz uma análise dessa decisão expondo que 
A Corte afirmou que o moderno processamento de dados pessoais configura uma grave ameaça à personalidade do indivíduo, na medida em que possibilita o armazenamento ilimitado de dados, bem como permite a sua combinação de modo a formar um retrato completo da pessoa, sem a sua participação ou conhecimento. Nesse contexto, argumentou que a Constituição alemã protege o indivíduo contra o indevido tratamento de dados pessoais, por meio do direito fundamental ao livre desenvolvimento da personalidade, segundo o qual o indivíduo tem o poder para determinar o fluxo de suas informações na sociedade. (MENDES, 2014, Edição Kindle)

Destarte, chega-se no momento em que se faz necessário abordar como o livre exercício da personalidade é de grande importância para uma sociedade democrática e como ela pode vir a ser afetada pela ingerência dos dados pessoais.

Como exposto acima, as novas técnicas do mercado publicitário podem ser aplicadas na corrida eleitoral, o perfilamento on-line torna possível uma classificação do eleitorado com base em suas informações pessoais, em que a propaganda eleitoral pode ser personalizada de acordo com as predileções daquele grupo de eleitores, proporcionando uma maior chance de persuadi-lo. Essa nova forma de executar a propaganda política é muito mais eficaz do que a propaganda política clássica e genérica, vez que aborda as prioridades específicas do eleitor (BOQUADY, 2018, p. 40).

Inobstante, não podemos deixar de observar que a internet ampliou a democratização do processo eleitoral, uma vez que estabeleceu um contato mais direto entre o candidato e o eleitor, todavia, da mesma forma que permite uma maior liberdade de informação, também possibilita a utilização maliciosa de técnicas que, quando descobertas por pessoas com intenções contrárias ao juridicamente tutelado, podem causar prejuízos à sociedade e à democracia.

Acontecimentos que marcaram os últimos anos demonstraram e alertaram sobre as possibilidades de manipulação da informação que podem afetar os direitos humanos e o processo democrático. O caso da Cambridge Analytica, empresa britânica especializada em marketing político que esteve presente nas eleições estadunidenses de 2016 (dois mil e dezesseis), baseou-se em dados coletados do Facebook, realizando a análise da personalidade dos indivíduos, com a formação de um perfil comportamental, para posteriormente delimitar o público e direcionar os conteúdos (OLIVEIRA, 2020, p. 173).

Para melhor situar a questão apresentada acima, Brittany Kaiser (2020, p. 87) expõe como os testes de personalidade foram utilizados pela empresa:

Usando ferramentas analíticas para entender as personalidades complexas dos indivíduos, os psicólogos conseguiriam definir o que os motivava à ação. Em seguida, a equipe de criação elaborou mensagens específicas para esses tipos de personalidade em um processo chamado "microtargeting comportamental". (KAISER, 2020, p. 87)

A utilização da informação como arma política tem uma linha tênue, vez que o limite entre mentiras, informação e imaginação está cada vez mais difuso. Desse modo, o que nasceu para democratizar o acesso à informação e à participação social em debates políticos, 
está fomentando a polarização, os discursos de ódio e a crise de legitimidade política. Toda a questão posta em cheque, evidentemente, não é consequência da evolução da internet, mas sim pelo uso que é feito dela e pela política que as sociedades estão construindo, trazendo à tona, por muitas vezes, o pior do ser humano (CASTELLS, 2003, p. 162).

Dessa forma, a proteção dos dados pessoais é requisito essencial para a concretização de uma democracia plena (MULHOLLAND, 2018, p. 173), pois o poder advindo das informações na sociedade contemporânea atinge múltiplos direitos do ser humano, os quais, por sua vez, são decorrentes da tutela da pessoa humana.

\section{CONSIDERAÇões FINAIS}

A partir do exposto, pode-se afirmar que o direito à privacidade assume cada vez mais importância na esfera da liberdade individual e da possibilidade de um efetivo aprofundamento da tomada de decisão coletiva, ou seja, em um avanço do processo democrático como um todo.

De um lado a liberdade individual, pois o indivíduo necessita, cada vez mais, não apenas ser deixado só, como se buscava no final do século XIX, mas sim ter informação suficiente para poder decidir sobre a utilização de seus dados, e poder livremente se desvencilhar dos organismos econômicos que desejam utilizar a informação para seus próprios ganhos. A privacidade se torna fundamental para que o indivíduo seja livre, e não refém de poucas corporações que conhecem os menores detalhes da vida de cada um, e o transformam em mais um perfil para direcionamento de conteúdo.

Da mesma forma, a própria democracia precisa do fortalecimento do direito à privacidade, uma vez que o referido profiling possibilita que a captação de dados pessoais seja utilizada para elaboração de macros perfis sociais, a partir dos quais é possível direcionar qualquer tipo de conteúdo com o maior impacto possível, desde aparentemente inofensivas propagandas de calçados, até notícias falsas capazes de impactar no resultado de eleições.

O que se espera é que as múltiplas acepções do conteúdo do direito à privacidade continuem sendo desenvolvidas, a fim de permitir uma real proteção, tanto do âmbito individual quanto do social. Sendo assim, não se deve abandonar a tradição jurídica já estabelecida, é importante ainda pensar que todos devem ter o direito de serem deixados sozinhos, se assim desejarem, além da necessidade de que sejam criados mecanismos efetivos para a proteção dos dados e da informação, principalmente nessa era em que a velocidade permite que quase instantaneamente se saiba do outro lado do mundo o que aqui aconteceu. Por fim é necessário pensar o direito fundamental à privacidade para o futuro, no qual a autodeterminação informativa tenha realmente o condão de conceder ao indivíduo a capacidade de se autodeterminar, ou seja, de saber exatamente as consequências do uso de seus dados, incluindo os diversos tipos de publicidade que são recebidos por meio do seu perfilamento (profiling).

Dessa forma, acredita-se que o direito à privacidade não pode ser enfraquecido, pelo contrário, é necessário pegar suas bases construídas historicamente e, a partir delas, lançar novos horizontes capazes de permitir uma sociedade livre, justa e democrática. 


\section{REFERÊNCIAS}

BAIÃO, Kelly Sampaio; GONÇALVES, Kalline Carvalho. A garantia da privacidade na sociedade tecnológica: um imperativo à concretização do princípio da dignidade da pessoa humana. Civilistica.com. Rio de Janeiro, a. 3, n. 2, jul.-dez./2014.

BIONI, Bruno Ricardo. Proteção de dados pessoais: as funções e limites do consentimento. Rio de Janeiro: Forense, 2019.

BOHRER, Igor Graeff. A Proteção de dados pessoais como direito da personalidade e seu risco diante do online profiling. 2019. 100 f. Trabalho de Conclusão de Curso (graduação) - Universidade Federal de Santa Catarina, centro de Ciências Jurídicas, Florianópolis, 2019.

BOQUADY, Natália Ribeiro Levy. Democracia e internet: os impactos das mídias digitais nas eleições de 2018. 2018. 86 f. Monografia (graduação) - Faculdade de Direito da Universidade de Brasília, Brasília, 2018.

BRASIL. Constituição (1988). Constituição da República Federativa do Brasil. Brasília, DF: Senado Federal, 1988. Disponível em: <http://www.planalto.gov.br/ccivil_03/ constituicao/constituicao.htm> Acesso em 03/06/2020.

CASTELLS, Manuel. A galáxia da internet: reflexões sobre a internet, os negócios e a sociedade. Tradução: Maria Luiza X. De A. Borges, Rio de Janeiro: Zahar, 2003.

CONSTANT, Benjamin. Da liberdade dos antigos comparada à dos modernos. Trad. Loura Silveira. Filosofia, 1819.

COSTA, Ramon Silva; OLIVEIRA, Samuel Rodrigues de. Os direitos da personalidade frente a sociedade de vigilância: privacidade, proteção de dados pessoais e consentimento nas redes sociais. In: Revista Brasileira de direito civil em perspectiva, Belém, v. 5, n. 2, p. 38, jul./dez. 2019.

DONEDA, Danilo. Da privacidade à proteção de dados pessoais: elementos da formação da Lei Geral de proteção de dados. 2.ed. São Paulo: Thomson Reuters Brasil, 2019.

FERRARI, Daniel Gomes; CASTRO, Leandro Nunes de. Introdução a mineração de dados. Saraiva Educação, 2017.

FOUCAULT, Michel. Vigiar e punir: nascimento da prisão; tradução de Raquel Ramalhete. 20. ed. Petrópolis, Vozes, 1987.

GADAMER, Hans-Georg. Verdade e Método. 15º ed. Vozes. Petrópolis/RJ. 2015. 
HOSTERT, Ana Cláudia. Proteção de dados pessoais na internet: a necessidade de lei específica no ordenamento jurídico brasileiro. 2018.87 f. Universidade Federal de Santa Catarina, Florianópolis, 2018.

LANIER, Jaron. Dez argumentos para você deletar suas redes sociais Trad. Bruno Casotti. 1. ed. Rio de Janeiro: Intrinseca, 2018.

LEONARDI, Marcel. Tutela e privacidade na internet. São Paulo: Saraiva, 2011.

KAISER, Brittany. Manipulados: como a Cambridge Analytica e o Facebook invadiram a privacidade de milhões e botaram a democracia em xeque Trad. Roberta Clapp e Bruno Fiuza. 1. ed. Rio de Janeiro: Harper Collins, 2020.

KREIN, Julia. Novos trustes na era digital: efeitos anticompetitivos do uso de dados pessoais pelo Facebook. Revista de Defesa da Concorrência, v. 6, n. 1, p. 198-231, mai. 2018.

LYON, David. The roots of the information Society idea, in: The media studies reader. Tim O’Sullivan; Yvonne Jewkes. (editores). London: Arnold, 1998.

MACHADO, Joana de Moraes Souza. A expansão do conceito de privacidade e a evolução na tecnologia de informação com o surgimento dos bancos de dados. Revista da AJURIS, v. 41, n. 134, p. 337/363, jun. 2014.

MACHADO, Fernando Inglez de Souza. Privacidade e proteção de dados pessoais na sociedade da informação: profiling e risco de discriminação. 2018. Dissertação de Mestrado. Pontifícia Universidade Católica do Rio Grande do Sul.

MARTINS, Pedro Bastos Lobo; HOSNI, David Salim Santos. O livre desenvolvimento da identidade pessoal em meio digital: para além da proteção da privacidade? In: POLIDO, Frabrício Bertini Pasquot; ANJOS, Lucas Costa dos; CHAVES, Luiza Couto. (Org.). Políticas, internet e sociedade. Belo Horizonte: Instituto de Referência em Internet e Sociedade (IRIS), 2019.

MARTINS, Leonardo. Tribunal Constitucional Federal alemão: decisões anotadas sobre direitos fundamentais. v. 1: Dignidade humana, livre desenvolvimento da personalidade, direito fundamental à vida e à integridade física, igualdade. São Paulo: Fundação Konrad Adenauer, 2016.

MENDES, Laura Schertel. Privacidade, proteção de dados e defesa do consumidor: linhas gerais de um novo direito fundamental. São Paulo: Saraiva, Edição Kindle, 2014.

MENDONÇA, Fernanda Graebin. O direito à autodeterminação informativa: a (des)necessidade de criação de um novo direito fundamental para a proteção de dados pessoais no 
Brasil. In: Seminário Internacional Demandas Sociais e Políticas Públicas na Sociedade Contemporânea, n. 11, 2014.

NETO, Elias Jacob de Menezes. Surveillance, democracia e direitos humanos: os limites do Estado na era do Big Data. 2016. Tese (Doutorado) - Universidade Vale do Rio dos Sinos, São Leopoldo, 2016.

MULHOLLAND, Caitlin Sampaio. Dados pessoais sensíveis e a tutela de direitos fundamentais: uma análise à luz da lei geral de proteção de dados (lei 13.709/18). Revista de Direitos e Garantias Fundamentais, Vitória, v. 19, n. 3, p. 173, set./dez., 2018.

OLIVEIRA, Bruna Pinotti Garcia. Inteligência Artificial e Proteção de dados: sobre a autodeterminação informativa e a manipulação informacional por machine learning. Humanidades e Tecnologias (FINOM), v. 26, n. 1, p. 162-186, jul./set. 2020.

ORGANIZAÇÃO DAS NAÇÕES UNIDAS (ONU). Declaração Universal de Direitos Humanos. Disponível em: <https://www.ohchr.org/EN/UDHR/Documents/UDHR_Translations/por.pdf $>$ Acesso em: 03/06/2020.

PEIXOTO, Erick Lucena Campos; JÚNIOR, Marcos Ehrhardt. Os desafios da compreensão do direito à privacidade no sistema jurídico brasileiro em face das novas tecnologias. Revista Jurídica Luso-brasileira-RJLB, Ano 6, nº 2, 2020.

PUPO, Alvaro de Carvalho Pinto. Privacidade, liberdade de expressão e proteção dos dados pessoais: uma perspectiva brasileira com base na jurisprudência do Supremo Tribunal Federal. 2017. Dissertação (Mestrado em Direito Civil) - Pontifícia Universidade Católica de São Paulo, Programa de Estudos Pós-Graduados em Direito, São Paulo, 2017.

RODOTÀ, Stefano. A vida na sociedade da vigilância: a privacidade hoje. Organização, seleção e apresentação de Maria Celina Bodin de Moraes. Tradução: Danilo Doneda e Luciana Cabral Doneda. Rio de Janeiro: Renovar, 2008.

SANTIN, Thais Dagostini. MAGRO, Diogo Dal. FORTES, Vinícius Borges. Estado de vigilância e democracia: uma análise da dimensão pública e privada da internet frente a violação do direito fundamental à privacidade. In: $4^{\circ}$ CONGRESSO INTERNACIONAL DE DIREITO E CONTEMPORANEIDADE. Anais... Santa Maria: Universidade Federal de Santa Maria, 2017, p. 14. Disponível em: <http://coral.ufsm.br/congressodireito/ anais/2017/6-11.pdf> Acesso em: 11/06/2020.

STRECK, Lênio. Hermenêutica Jurídica e(m) Crise. $11^{\circ}$ ed. Livraria do Advogado. Porto Alegre. 2014. 
WARREN, Samuel; BRANDEIS, Louis. The Right to Privacy. Harvard Law Review. Vol. 4. No. 5. 1890.

\section{ANDREI Fredes}

Doutor em Direito mediante cotutela internacional pela Pontifícia Universidade Católica do Rio Grande do Sul (PUCRS) e pela Universidad de Granada (UGR). E-mail: fredesandrei@gmail.com

\section{Mariana Borges}

Advogada especialista em Direito e Tecnologia. E-mail: mari_borges52@hotmail.com

Submetido em: 5-1-2021

Aceito em: 19-3-2021 